\title{
Introduction to Ins and outs of endovenous laser ablation by the associate guest editors
}

\author{
H. A. Martino Neumann • Martin J. C. van Gemert
}

Received: 7 November 2013 / Accepted: 10 November 2013 /Published online: 24 December 2013

(C) Springer-Verlag London 2013

Lasers in Medical Science was launched in 1986 "to provide a new avenue of communication for discussion and exchange of information among various clinical disciplines and between clinician and non-clinician" [1]. In this special series of articles, the associate guest editors have attempted to invite scientists from the clinic as well as from the lab to present the reader with the ins and outs of endovenous laser ablation.

Not too long after its invention in 1960, lasers have taken an important place in the daily medical practice. The skin is the organ par excellence to be exposed to laser light with the aim to treat for dermatological as well as cosmetic requests from patients.

Varicose veins are one of the most common human diseases. Prevalence of clinical varicose veins ranges from $10-40 \%$ in man and $26-32 \%$ in women. The repeated variation of these estimates [2-5] can at least partially be explained by differences in the disease definition, the study population, and the methods of estimation. Varicose veins are hemodynamically characterized by reflux. Serious reflux leads to venous hypertension and finally, a leg ulcer. Varicose veins are common in $77 \%$ of the women above 70 years of age and leg ulcerations occur in 4 $5 \%$ of the patients older than 80 years $[6,7]$.

Surgical stripping, introduced by the American surgeon Keller in 1905 [8], has been for over 100 years the gold standard of treatment for varicose veins. However, new technology offers the physician the possibility to introduce a laser fiber into the varicose veins and to perform endovenous laser ablation

\section{H. A. M. Neumann}

Department of Dermatology, Erasmus University Medical Center, Rotterdam, The Netherlands

\section{J. C. van Gemert ( $\square)$}

Department of Biomedical Engineering and Physics, Academic

Medical Center, University of Amsterdam,

Amsterdam, The Netherlands

e-mail: m.j.vangemert@amc.uva.nl procedures. And, a revolution has taken place in favor of the varicose vein patient. No hospitalization, no general anesthesia, less postoperative complaints like pain, and also a significant reduction in costs for the treatment thanks to the medical laser.

We, the associate guest editors, are proud to offer in this special a broad overview of the recent developments in ins and outs of endovascular venous laser ablation. The contribution of clinical and non-clinical scientists, often in one paper in this special, is actually unique for this subject. We have invited very carefully the most prominent leaders in this field to write the articles. As endovenous laser ablation is a hot item in phlebology, we believe that this special series of articles contributes seriously to a better understanding and future fine tuning of this elegant therapy for a broad group of patients. The socialeconomic positive impact of this laser technique is of general societal importance. We hope that the readers will find the same pleasure in reading these articles as we had in editing them.

Finally, we reviewed very carefully all invited papers ourselves and, in case of co-authorship, we asked others to give their opinion on the manuscript and again, we very carefully complied with their critiques.

\section{References}

1. Bown SG, Carruth JAS, Jori G, Svaasand LO (1986) Lasers in medicine introducing the new journal. Lasers Med Sci 1(1):3

2. Evans CJ, Fowkes FG, Ruckley CV, Lee AJ (1999) Prevalence of varicose veins and chronic venous insufficiency in men and women in the general population: Edinburgh Vein Study. J Epidemiol Community Health 53(3):149-153

3. Criqui MH, Jamosmos M, Fronek A, Denenberg JO, Langer RD, Bergan J et al (2003) Chronic venous disease in an ethnically diverse population: the San Diego Population Study. Am J Epidemiol 158(5): $448-456$

4. Abramson JH, Hopp C, Epstein LM (1981) The epidemiology of varicose veins. A survey in western Jerusalem. J Epidemiol Community Health 35(3):213-217 
5. Coon WW, Willis PW, Keller JB (1973) Venous thromboembolism and other venous disease in the Tecumseh community health study. Circulation 48(4):839-846

6. Brand FN, Dannenberg AL, Abbott RD, Kannel WB (1988) The epidemiology of varicose veins: the Framingham Study. Am J Prev Med 4(2):96-101
7. Margolis DJ, Bilker W, Santanna J, Baumgarten M (2002) Venous leg ulcer: incidence and prevalence in the elderly. J Am Acad Dermatol 46(3):381-386

8. Keller WL (1905) A new method of extirpating the internal saphenous and similar veins in varicose conditions. A preliminary report. N Y J Med 82:385-386 